\title{
A Simple, Potential-Free Model to Calculate Elastic Constants of Solids at High Temperature
}

\author{
Madan Singh", ${ }^{1, *}$ Himanshu Narayan ${ }^{1}$, Munish Kumar $^{2}$ \\ ${ }^{1}$ Department of Physics and Electronics, National University of Lesotho, Roma, 180, Lesotho, Southern Africa \\ ${ }^{2}$ Department of Physics, G.B. Pant University of Ag. \& Technology, Pantnagar, 263145, Uttranchal, India
}

\begin{abstract}
A simple method for the determination of temperature dependent second order elastic constants (SOEC) of $\mathrm{MgO}, \mathrm{CaO}, \mathrm{Mg}_{2} \mathrm{SiO}_{4}$ and Grossular garnet $\left[\mathrm{Ca}_{3} \mathrm{Al}_{2}\left(\mathrm{SiO}_{4}\right)_{3}\right]$ using a potential free model based on thermodynamical relationships, has been proposed. The equations developed here are based on the linear relationship between elastic constants at temperatures higher than the Debye temperature. The extrapolated data for elastic constants at very high temperatures obtained in the present study are useful to understand the thermoelastic properties of given solids. It is found that the calculated values of elastic constants, in general, decrease with temperature. The theoretical predictions incorporating the concept of Debye temperature, reported in this paper, are well supported by the available experimental data. The proposed empirical relationship provides a method to estimate the thermoelastic properties of geophysical minerals and solids at high temperature range.
\end{abstract}

Keywords Elastic Constants, High Temperature, Thermodynamical Relationships

\section{Introduction}

A thorough understanding of the elastic properties of various solids and their variations with temperature is essential in the study of geophysical and geochemical theories of earth interior[1],[2]. Behaviour of minerals under extreme conditions of temperature plays an important role in understanding the dynamics and evolution of lower mantle of earth. Knowledge of elastic constants is essential to interpret the thermodynamic and thermoelastic properties of minerals and solids at high temperatures. The study of temperature dependence of elastic constants for solids has been a subject of wide interest[3],[4]. Therefore, a number of theoretical as well as experimental physicists are currently engaged in the investigations related to elastic constants of diverse materials, employing a wide variety of approaches[5-10]. The elastic constants of some minerals have been calculated starting from the room temperature to higher temperatures, but there are deviations from experimental results after Debye temperature[10-12]. As far as the theoretical studies are concerned, methods like the Monte-Carlo and lattice dynamical simulation using a rigid body model[13] and three-body potential model[14] have been adopted with reasonable amount of success. Nevertheless, there have been some serious weaknesses in these models. For example, in the three-body potential model[14], the short-range overlap potential parameters

* Corresponding author:

m.singh@nul.ls (Madan Singh)

Published online at http://journal.sapub.org/ajcmp

Copyright (C) 2012 Scientific \& Academic Publishing. All Rights Reserved calculated at $300 \mathrm{~K}$, have been used in the high temperature range as such, presuming to be independent of temperature. Moreover, the Van der Waal's coefficient calculated from the lattice sums was also taken as temperature independent. The interior separations $(r)$ in various minerals and crystals varies with temperature (Vandana et al[15]) and therefore, it is imperative to consider the short range overlap, as well as the Van der Waal's interaction parameters, as temperature dependent quantities.

In order to overcome the above mentioned discrepancies in existing theories, and to make the theory simpler we have employed a potential free model based on thermodynamical relationships. In this article, we report temperature dependent second order elastic constants (SOEC) of some solids calculated in the higher temperature $\left(T>T_{D} ; T_{D}\right.$ is the Debye temperature)[16] region, using a simple and straightforward theoretical model based on some approximations. This model may be used to calculate the thermoelastic properties of any type of minerals. We have chosen four different crystals, viz., $\mathrm{MgO}, \mathrm{CaO}, \mathrm{Mg}_{2} \mathrm{SiO}_{4}$ and Grossular garnet $\left[\mathrm{Ca}_{3} \mathrm{Al}_{2}\left(\mathrm{SiO}_{4}\right)_{3}\right]$, to test the outcome of our theory. Among these, $\mathrm{MgO}$ and $\mathrm{CaO}$ are common oxides, $\mathrm{Mg}_{2} \mathrm{SiO}_{4}$ is a material of geophysical importance, and Grossular garnet is a well-known mineral. Basically all these four solids possess cubic crystal structure. However, $\mathrm{MgO}$ and $\mathrm{CaO}$ have octahedral; $\mathrm{Mg}_{2} \mathrm{SiO}_{4}$ has hexoctahedral, and Grossular garnet, dodecahedral coordination geometry. Experimentally determined values of elastic constants for $\mathrm{MgO}, \mathrm{CaO}, \mathrm{Mg}_{2} \mathrm{SiO}_{4}$ and Grossular garnet solids are available in the temperature range starting from $300 \mathrm{~K}$ up to $1800 \mathrm{~K}, 1200 \mathrm{~K}, 1700 \mathrm{~K}$ and $1350 \mathrm{~K}$, respectively[3].

The method of analysis is given in section 2 and results 
are discussed and compared with experimental data in section 3 .

\section{Method of Analysis}

Starting with the expressions for SOEC[17], as employed on the cubic crystals under isotropic pressure[18]:

$$
\begin{aligned}
& C_{11}=C_{11}^{0}-p_{\text {phonon }}, \\
& C_{12}=C_{12}^{0}+p_{\text {phonon }},
\end{aligned}
$$

and,

$$
C_{44}=C_{44}^{0}-p_{\text {phonon }} \text {. }
$$

Here, $C_{i j}$ is the SOEC at temperature $T$, and $C_{i j}^{0}$ represents their values at $300 \mathrm{~K}\left(T_{0}\right)$. The quantity $p_{\text {phonon }}$ is phonon pressure, equivalent to the thermal pressure $\left(p_{T h}\right)$, which may be evaluated using the following relationship[3],[19],[20]:

$$
\left(\frac{\partial p}{\partial T}\right)_{V}=\left(\frac{\partial p_{T h}}{\partial T}\right)_{V}=\alpha_{0} K_{T}^{0},
$$

Where, $V$ is the volume. Also, $\alpha_{0}$ and $K_{T}^{0}$ are the coefficient of volume thermal expansion, and bulk modulus, respectively, at $T=T_{0}$ (i.e., at $300 \mathrm{~K}$ ).

One can get the expression for $p_{T h}$ from Eq. 4 as,

$$
p_{T h}=\int_{T_{0}}^{T} \alpha_{0} K_{T}^{0} d T,
$$

Or,

$$
p_{T h}=\alpha_{0} K_{T}^{0}\left(T-T_{0}\right) .
$$

The Anderson-Gruneisen parameter at a given temperature $T$ is defined as[19],

$$
\delta_{T}=-\frac{1}{\alpha K_{T}}\left(\frac{d K_{T}}{d T}\right)_{P},
$$

Which may be used to determine the rate of change of bulk modulus $K_{T}$ with respect to temperature as,

$$
\left(\frac{d K_{T}}{d T}\right)=-\alpha K_{T} \delta_{T},
$$

at constant pressure. Integration of Eq. 8 leads to the expression for bulk modulus as a function of temperature as follows,

$$
K_{T}=K_{T}^{0}\left[1-\alpha_{0} \delta_{0}\left(T-T_{0}\right)\right] .
$$

We assume $\delta_{T}$ and $\alpha K_{T}$ as temperature independent quantities, which has already been assumed empirically in the case of solids studied in[1]. The quantity $\alpha_{0} K_{T}^{0}\left(T-T_{0}\right)$ involved in this equation is thermal pressure $p_{T h}$ as obtained in Eq. 6 above. Obviously, $p_{T h}$ would change with temperature resulting in change in volume. Accordingly, the bulk modulus, as well as other elastic constants, would be temperature dependent. The same inference may also be drawn directly from Eqs. 1-3.

Presuming that similar trend of variation with respect to temperature is followed by other elastic constants also; one can generalize Eq. 9[21] to obtain the expressions for the latter, which may be collectively written as:

$$
\frac{m}{m_{0}}=\left[1-\alpha_{0} \delta_{m}^{0}\left(T-T_{0}\right)\right]
$$

Where, $m$ represents any of the elastic moduli such as $C_{11}, C_{12}, C_{44}$, etc. This expression nicely holds in the $T>T_{0}$ region for the solids whose Debye temperature is near $T_{0}$ (room-temperature, $300 \mathrm{~K}$ ), such as the ionic crystals $\mathrm{NaCl}, \mathrm{KCl}$, etc.[22]. However, when $T_{D}>T_{0}$, it holds only up to $T_{D}$ for the calculated values of some SOEC, such as, $C_{12}$, and then some deviations may occur.

Equation 10 therefore, may be modified to accommodate the $T>T_{D}$ temperature regime by replacing the values of input parameters with those corresponding to $T_{D}$. In the modified picture, the relevant expressions for SOEC at $T>T_{D}$ can be collectively written as follows:

$$
\frac{C_{i j}}{C_{i j}^{D}}=\left[1-\alpha_{D} \delta_{i j}^{D}\left(T-T_{D}\right)\right],
$$

In Eq. $11, \delta_{i j}^{D}$ are constants corresponding to $C_{i j}$, defined as[23],

$$
\delta_{i j}^{D}=-\frac{1}{\alpha_{D} C_{i j}^{D}}\left(\frac{d C_{i j}}{d T}\right)_{D},
$$

and, the letter $D$ refers to values of the corresponding quantities at Debye temperature, $T_{D}[16]$.

Table 1. Values of Debye temperature $T_{D}$ and the input parameters (near $T_{D}$ ) used in calculations[3]

\begin{tabular}{ccccccc}
\hline Parameters (units) & $\mathrm{MgO}$ & $\mathrm{CaO}$ & & $\mathrm{Mg}_{2} \mathrm{SiO}_{4}$ & Grossular Garnet \\
\hline$T_{D}$ & $(\mathrm{~K})$ & 945 & 671 & 763 & 824 \\
$\alpha_{D}$ & $\left(10^{-5} \mathrm{~K}^{-1}\right)$ & 4.38 & 3.92 & 3.59 & 2.78 \\
$\delta_{D}$ & & 4.78 & 5.07 & 5.47 & 4.64 \\
$C_{11}^{D}$ & $\left(10^{10} \mathrm{~N} / \mathrm{m}^{2}\right)$ & 26.19 & 20.12 & 30.03 & 30.02 \\
$C_{12}^{D}$ & $\left(10^{10} \mathrm{~N} / \mathrm{m}^{2}\right)$ & 9.86 & 5.866 & 6.07 & 9.04 \\
$C_{44}^{D}$ & $\left(10^{10} \mathrm{~N} / \mathrm{m}^{2}\right)$ & 14.81 & 7.718 & 6.01 & 9.76 \\
$\left(d C_{11} / d T\right)_{D}$ & $\left(10^{7} \mathrm{~N} / \mathrm{m}^{2} / \mathrm{K}\right)$ & -6.20 & -4.60 & -4.0 & -3.7 \\
$\left(d C_{12} / d T\right)_{D}$ & $\left(10^{7} \mathrm{~N} / \mathrm{m}^{2} / \mathrm{K}\right)$ & -0.20 & 0.15 & -1.3 & -0.2 \\
$\left(d C_{44} / d T\right)_{D}$ & $\left(10^{7} \mathrm{~N} / \mathrm{m}^{2} / \mathrm{K}\right)$ & -1.60 & -0.72 & -1.35 & -1.1 \\
\hline
\end{tabular}


Table 2. Values of slopes of the theoretical lines. Corresponding values of slopes of the best-fit straight lines to experimental data are shown within brackets

\begin{tabular}{ccccc}
\hline Parameters & MgO & $\mathbf{C a O}$ & $\mathbf{M g}_{2} \mathbf{S i O}_{\mathbf{4}}$ & Grossular Garnet \\
\hline$\left(10^{\prime} \mathrm{N} / \mathrm{m}^{2} / \mathrm{K}\right)$ & & & -4.150 & -3.700 \\
$d C_{11} / d T$ & -5.855 & -4.850 & $(-4.530)$ & -3.920 \\
& $(-6.020)$ & $-0.630)$ & -0.400 \\
$d C_{12} / d T$ & -0.463 & 0.348 & -0.001 & $(-0.354)$ \\
$d C_{44} / d T$ & $(-0.417)$ & $(0.060)$ & $(-0.001)$ & -1.100 \\
$d C_{s} / d T$ & -1.250 & -0.700 & -1.300 & $(-1.160)$ \\
& $(-1.680)$ & $(-0.799)$ & $(-1.350)$ & -1.680 \\
& -3.300 & -2.600 & -1.550 & $(-1.810)$ \\
\hline
\end{tabular}

From this simple theory, taking $T_{D}$ as the reference temperature, one can calculate the values of SOEC that are in excellent agreement with the experimental data. The constants $\delta_{i j}^{D}$ are calculated using Eq. 12 and the input parameter[3] given in Table 1, and then substituted with other quantities in Eq. 11 to obtain the theoretical values of SOEC at different temperatures. The values of $d C_{i j} / d T$ were not available, and therefore, we have used the interpolated values of these quantities at Debye temperature, obtained from the data given in Ref.[3]. These values are listed in Table 1.

\section{Results and Discussion}

Many authors have reported theoretically calculated values of SOEC taking $T_{0}(300 \mathrm{~K})$ as the reference temperature[7],[8]. Therefore, we first calculated all the SOEC values, viz., $C_{11}, C_{12}, C_{44}$ and $C_{s}$ for four different solids $\mathrm{MgO}, \mathrm{CaO}, \mathrm{Mg}_{2} \mathrm{SiO}_{4}$ and Grossular garnet $\left[\mathrm{Ca}_{3} \mathrm{Al}_{2}\left(\mathrm{SiO}_{4}\right)_{3}\right]$, taking the reference temperature at $300 \mathrm{~K}$ instead of $T_{D}$, to understand the inconsistency. To accomplish this, we used room temperature values of the input parameters in Eq. 11. The values of SOEC thus calculated were found to agree to great extent with the available experimental data for all the four solids considered in this work. It was observed that the values of SOEC decrease with increasing $T$ in all four solids, in concurrence with the experimentally reported values, except for the case of $C_{12}$ in $\mathrm{MgO}$ and $\mathrm{CaO}$. Experimentally, it was observed that for $\mathrm{MgO}, C_{12}$ slowly increases with temperature up to $900 \mathrm{~K}$, and then decreases[3]. Mathematically, the slow initial increase of $C_{12}$ is associated with a positive $\left(d C_{12} / d T\right)_{0}$, which is because of a negative value of $\delta_{12}^{0}$, or vice-verse. At higher temperature $(T>900 \mathrm{~K}), C_{12}$ decreased with temperature, which was a reflection of positive $\delta_{12}^{0}$. In the case of $\mathrm{CaO}$, the dependence of $C_{12}$ (experimental) on temperature becomes very small, after about $650 \mathrm{~K}$. It may be noted that the change in trend occurs near the respective values of $T_{D}$, i.e., $945 \mathrm{~K}$ (for $\mathrm{MgO}$ ) and $671 \mathrm{~K}$ (for $\mathrm{CaO}$ )[3]. Therefore, the observed change in trend must essentially be associated with $T_{D}$. Like all physical quantities associated with the lattice phonons in solids, $p_{T h}$ must also change its temperature dependence at $T_{D}$. Effectively, the SOEC that are dependent on $p_{T h}$ (Eqns. 1-3) should also be expected to change their dependence on temperature beyond $T_{D}$.
In order to overcome this discrepancy, we changed the reference temperature from $300 \mathrm{~K}$ to the respective Debye temperature $T_{D}$ of the solids in Eq. 11, and calculated the SOEC again. Accordingly, the input parameters corresponding to $T_{D}$ (Table 1) were used in the calculations. Due to the unavailability of experimental SOEC data beyond $1800 \mathrm{~K}, 1200 \mathrm{~K}, 1700 \mathrm{~K}$ and $1350 \mathrm{~K}$, for $\mathrm{MgO}, \mathrm{CaO}, \mathrm{Mg}_{2} \mathrm{SiO}_{4}$ and Grossular garnet, we calculated the values of elastic constants only up to 1800 , 1600,1700 and $1700 \mathrm{~K}$, respectively, for proper comparison of results.

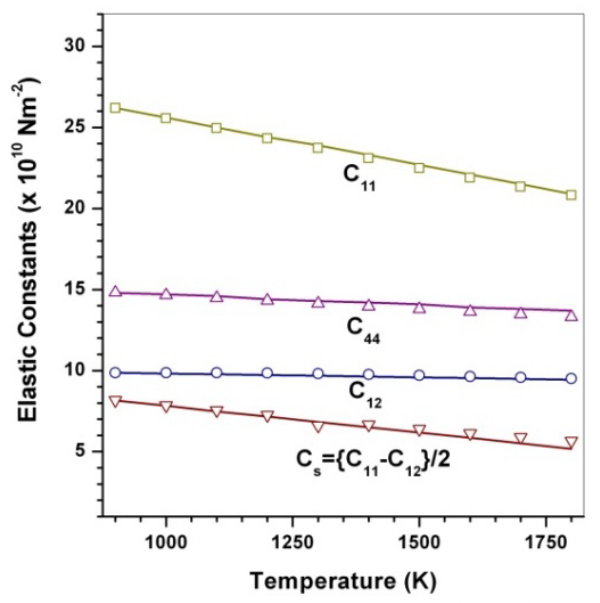

Figure 1. Variation of $C_{11}, C_{12}, C_{44}$ and $C_{s}\left(10^{10} \mathrm{~N} / \mathrm{m}^{2}\right)$ for $\mathrm{MgO}$ with temperature. Values calculated in the present study using equation (11) are shown with continuous lines and the experimental data[3], with points

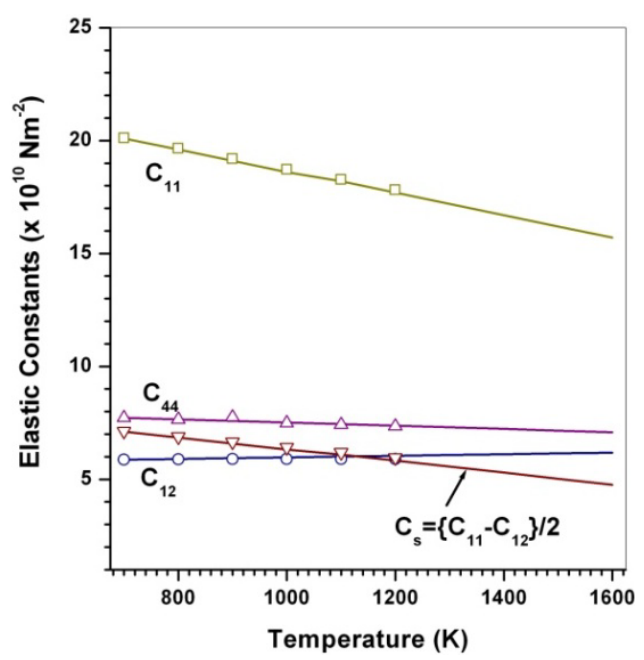

Figure 2. Variation of $C_{11}, C_{12}, C_{44}$ and $C_{s}\left(10^{10} \mathrm{~N} / \mathrm{m}^{2}\right)$ for $\mathrm{CaO}$ with temperature. Values calculated in the present study using equation (11) are shown with continuous lines and the experimental data[3], with points 


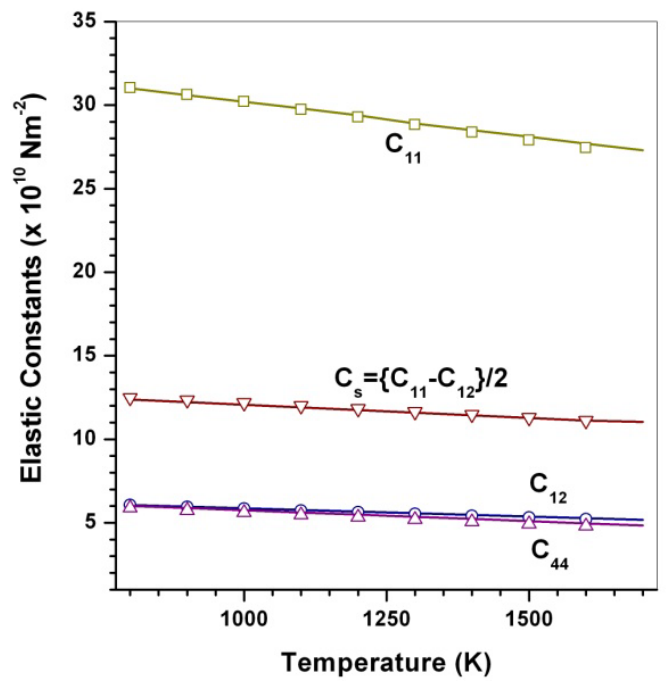

Figure 3. Variation of $C_{11}, C_{12}, C_{44}$ and $C_{s}\left(10^{10} \mathrm{~N} / \mathrm{m}^{2}\right)$ for $\mathrm{Mg}_{2} \mathrm{SiO}_{4}$ with temperature. Values calculated in the present study using equation (11) are shown with continuous lines and the experimental data[3], with points

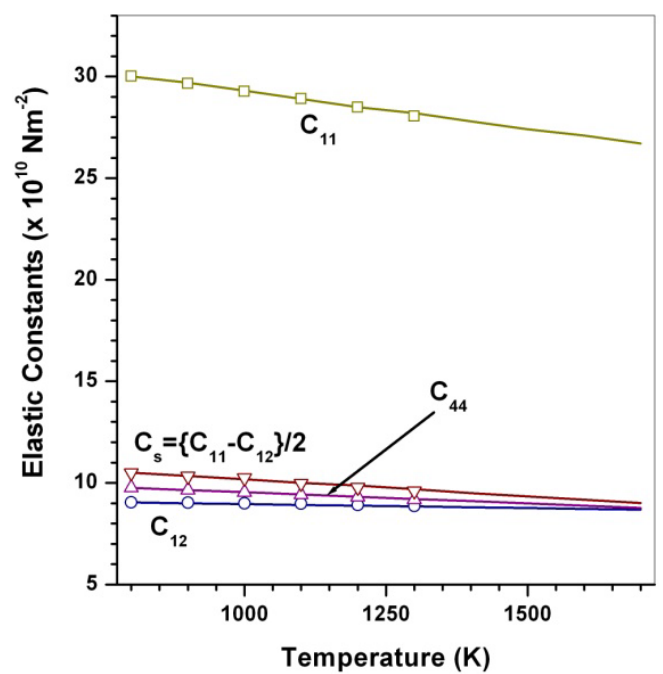

Figure 4. Variation of $C_{11}, C_{12}, C_{44}$ and $C_{s}\left(10^{10} \mathrm{~N} / \mathrm{m}^{2}\right)$ for Grassular garnet with temperature. Values calculated in the present study using equation (11) are shown with continuous lines and the experimental data[3], with points

The variation of $C_{11}$ with temperature is found to be large but for $C_{12}$, it is small, and for $C_{44}$ even smaller. This is because the constant $C_{11}$ represents elasticity in length, and a longitudinal strain produces a change in volume without any change in shape. The volume change is closely related to temperature and therefore, produces a large change in $C_{11}$. On the other hand, $C_{12}$ and $C_{44}$ are related to elasticity in shape without the change in volume, which makes $C_{12}$ and $C_{44}$ less temperature sensitive.

Variations of the elastic constants $C_{11}, C_{12}, C_{44}$ and $C_{s}$ with temperature, for $T>T_{D}$, calculated using $T_{D}$ as the reference temperature, are shown in Figs. 1-4 for the MgO, $\mathrm{CaO}, \mathrm{Mg}_{2} \mathrm{SiO}_{4}$ and Grossular garnet, respectively. For comparison, the experimentally determined values of the corresponding elastic constants are also shown. It may easily be noted that the calculated values, in general, are in very good agreement with the available experimental data[3]. This observation has been consolidated with the estimation of slopes of each of the theoretical lines, as well as that of the best fitting straight lines to experimental data. Values of these slopes, which essentially represent the rate with which a given SOEC varies with respect to temperature, are listed in Table 2. A comparison between theoretical, and the corresponding experimental, values of the slopes immediately reveals the significant agreement between the two. Moreover, since $C_{12}$ is a monotonically decreasing function of temperature (Eq. 11), when the reference temperature is set at $T_{D}$, as we have done in our calculations, the theory is expected to agree with the experimental data even up to the melting temperature of the solid under consideration.

Finally, so far as the validity of theory in the temperature regime $T_{0}<T<T_{D}$ is concerned, values obtained with $T_{D}$ as the reference temperature are better than those obtained with $T_{0}$ as the reference. This is evidenced from the fact that the maximum observed difference in theoretical and experimental values of $C_{12}$ for $\mathrm{MgO}$ and $\mathrm{CaO}$, are larger with the latter reference temperature. Therefore, it can be concluded that the theory reported here is valid at higher temperatures, especially beyond the Debye temperature.

\section{Conclusions}

The Variation of SOEC of solids has been investigated on the basis of Anderson equation[19] with first order approximations. Good conformity between calculated and experimental values of SOEC from Debye temperature to higher temperature for solids under study reveals the validity of relationships used in the present analysis. The simple method developed in the present work is free from the theory of potential, and the results obtained are in good agreement with complete simulation studies as well. On the basis of overall descriptions, the method was found to be better than those reported earlier[10],[12], as far as the simplicity and applicability are concerned. The approach is independent of crystal structure and may be extended to the more complex solids like minerals of geophysical importance up-to their respective melting temperature. Due to the simplicity of calculations and potentially wider applicability, this model might be used in calculating the thermoelastic properties of various nanomaterials[24],[25]. More work in this direction is in progress.

\section{ACKNOWLEDGEMENTS}

The authors are thankful to the referee for his valuable comments, which have been useful in revising the manuscript.

\section{REFERENCES}


[1] D.G. Isaak, O.L. Anderson, T. Goto, "Measured Elastic Modules of Single Crystal MgO up to $1800 \mathrm{~K}$ ", Phys. Chem. Minerals, vol. 16, pp. 704, 1989.

[2] D.G. Isaak, O.L. Anderson, ?? Hoda, "Thermal Expansion and High Temperature Elasticity of Calcium-rich Garnets", Phys. Chem. Minerals, vol. 19, pp. 106, 1992.

[3] O.L. Anderson, D.G. Isaak, Mineral Physics and Crystallography, A Hand Book of Physical Constants (American Geophysics), p-64, 1995.

[4] B.P. Singh, H. Chandra, "Temperature Dependence of Elastic Moduli and Isobaric Volume Expansion of Ionic Solids", Physica B, vol. 358, pp. 1, 2005.

[5] Madan Singh, P.P Singh, M. Kumar, B.R.K.Gupta, "Temperature and Pressure Dependence of Elastic Constants", High Temp- High Press., vol. 33, pp. 199, 2001.

[6] A.K. Upadhyay, B. S. Sharma, "Analysis of Sound Velocities and Elastic Moduli of Some Minerals", Ind. J. Pure Appl. Phys., vol. 49, pp. 30, 2011.

[7] P.P. Singh, M. Kumar, "Temperature Dependence of Bulk Modulus and Second Order Elastic Constants", Physica B, vol. 344, pp. 41, 2004.

[8] S.K. Srivatava, S.K. Sharma, "Elastic Constants for $\mathrm{NaCl}$ and $\mathrm{KCl}$ solids at high Temperatures", Phys. Chem. Solids, vol. 68, pp. 1648, 2007.

[9] B.K. Sarkar, A.S. Verma, R.C. Gupta, "Temperature Dependence of Elastic Constants for Ionic Solids", Physica B, vol. 404, pp. 4106, 2009.

[10] S.K. Srivastava, Pallavi Sinha, "Thermal Expansivity at High Temperatures for Ionic Solids", Ind. J. Pure Appl. Phys., vol. 49, pp. 195, 2011.

[11] A. Vijay, "Temperature Dependence of Elastic Constants and Volume Expansion for Cubic and Noncubic Minerals", Physica B, vol. 349, pp. 62, 2004.

[12] Zheng-Hua Fang, 'Temperature Dependence of Elastic Moduli for $\mathrm{MgO}$ and $\mathrm{CaO}$ ", Solid State Sci., vol. 10, pp. 950, 2008.
[13] Z.Gong, G.K. Horton, E.R. Cowley, "Thermal Expansion of Ionic Materials at High Temperature", Phys. Rev. B, vol. 38 , pp. $10820,1998$.

[14] R.K. Singh, C.N. Rao, S.P. Sanyal, "Temperature Dependence of Elastic Constants of Some Fluoride Crystals", Phys. Rev. B, vol. 39, pp. 13493, 1989.

[15] Vandana Pal, Madan Singh, B.R.K. Gupta, "Analysis of Thermal Expansion Coefficients Under the Effect of High Temperature for Minerals", J. Phys. Chem. Solids, vol. 60, pp. $1895,1999$.

[16] S.K. Srivastava, "Relationship Between Elastic Constants and Thermal Expansivity for Ionic Solids", Physica B, vol. 387, pp. 396, 2007.

[17] D.C. Wallace, Ed, Solid Stats Physics, Academic Press, New York, vol. 25, pp. 301, 1970.

[18] U.C. Srivastava, "Temperature Dependence of Second Order Elastic Constants of NaCl", Phys Stat Sol. (b), vol. 100, pp. 641, 1980.

[19] O.L. Anderson, Equation of State of Solid for Geophysics and Ceramic Science, Oxford Univ. Press, Oxford, 1995.

[20] O.L. Anderson, D.G. Isaak, Yamamoyo, "Anharmonicity and the Equation of State for Gold", J. Appl. Phys., vol. 65, pp. $1534,1989$.

[21] J.L. Tallon, "The Thermodynamics of Elastic Deformation Equation of State of Solids", vol. 41, pp. 837, 1980.

[22] Pallavi Sinha, S.K. Srivastava, "Temperature Dependence of Elastic Constants and thermal Pressure for Ionic Solids", Physica B, vol. 405, pp. 1197, 2010.

[23] M. Kumar, S.S. Bedi, "High Temp-High Press Study of Elastic Properties of Alkaline Earth Oxides", J. Phys Chem Solids, vol. 27/28, pp. 595, 1995/1996.

[24] Jeewan Chandra, Deepika Kandpal, B.R.K. Gupta, "Study of Thermoelastic Properties of Nanomaterials Under High Temperature", Physica B, vol. 404, pp. 1087, 2009.

[25] Uma D.Sharma, Munish Kumar, "Analysis of Equation of State for Nanomaterials”, Physica B, vol. 406, pp. 794, 2011. 